\title{
Study of High Purity Cobalt Carbonate Nanocrystals Production by Microemulsion as Batteries Precursors
}

\author{
Mulaja Tshakatumba Constantin*, Tshipeshi Makina Héritier, Ngoy Moïse Raphael Moramess, \\ Mwema Mutamba Edouard
}

Metallography and Materials, Metallurgy, Polytechnics, University of Lubumbashi, Lubumbashi, DRC

Email: *tshaka021@yahoo.fr

How to cite this paper: Constantin, M.T., Héritier, T.M., Moramess, N.M.R. and Edouard, M.M. (2021) Study of High Purity Cobalt Carbonate Nanocrystals Production by Microemulsion as Batteries Precursors. Journal of Minerals and Materials Characterization and Engineering, 9, 316-326. https://doi.org/10.4236/jmmce.2021.93022

Received: March 13, 2021

Accepted: May 28, 2021

Published: May 31, 2021

Copyright $\odot 2021$ by author(s) and Scientific Research Publishing Inc. This work is licensed under the Creative Commons Attribution International License (CC BY 4.0).

http://creativecommons.org/licenses/by/4.0/

(c) (i) Open Access

\begin{abstract}
The precipitation of cobalt carbonate nanocrystals was achieved through the reaction of a pure and rich solution of cobalt sulphate $\left(\mathrm{Co}^{2+}: 16.80 \mathrm{~g} / \mathrm{l}\right)$ with a solution of carbonate solution $(200 \mathrm{~g} / \mathrm{l})$. A surfactant was added to the reacting mixture in order to control the shape and size of generated crystallites. Two parameters were then varied i.e., the weight of surfactant agent and the precipitation time in accordance with Taguchi's L4 full experimental procedure $\left(2^{2}\right)$. Chemical and structural characterizations tests of the obtained precipitates were done through X-Rays Fluorescence (XRF), Scanning Electron Microscopy (SEM) and X-Rays Diffractometer (XRD); whereas the size of crystallites was assessed according to the Laue-Scherrer formula. The results obtained from the variance analysis (ANOVA) indicated an optimal size of cobalt carbonate's crystallites of $13 \mathrm{~nm}$ with a cobalt content of $44.35 \%$ (equivalent to $89.45 \%$ of $\mathrm{CoCO}_{3}$ ) at ambient temperature under the following conditions: $\mathrm{pH}=7$; Mixing speed: $800 \mathrm{tr} / \mathrm{min}$; Surfactant weight: $8 \mathrm{~g}$; and a mixing time: 10 minutes. SEM images revealed an agglomeration of the obtained nanocrystals due to suspected drying conditions i.e., drying temperature and drying atmosphere. It is suggested that the experiment should be conducted under neutral conditions at a temperature below that of cobalt carbonate's decomposition $\left(181.41^{\circ} \mathrm{C}\right)$.
\end{abstract}

\section{Keywords}

Nanocrystals, Cobalt Carbonate, Microemulsion, Batteries

\section{Introduction}

The synthesis of inorganic materials with nanoscale morphology has aroused 
considerable interests around the globe, making nanoscience an important field in modern research. Popular opinion has projected it to be at the core of the $5^{\text {th }}$ global revolution [1] [2]. Metal salts constitute an important category in nanoscience owing it to their large surface area and their stable chemical and thermal proprieties [1] [3] [4] [5].

Cobalt carbonate nanocrystals, precursor to cobaltous oxide $(\mathrm{CoO})$, are of evolving interest due to their exceptional properties. They are widely used in rechargeable batteries for electric vehicles (49\% in 2018), in catalysis and in the production of magnetic materials owing it to their physical, electrical and chemical properties [4]-[9].

There are several nanocrystals synthesis methods, including [10]-[15]:

- Physical methods such as the vapor condensation, the thermal evaporation, the laser method, the jet pyrolysis method, the mechanosynthesis and the thermochemical decomposition.

- Chemical methods: such as the sol-gel, the precipitation and the microemulsion methods.

In this research, the microemulsion method was used as it is to be one of the most promising technics for the synthesis of nanomaterials [10] [16]-[21].

\section{Experimental Procedure}

\subsection{Reagents Used}

A pure sulphate solution and rich in cobalt $\left(\mathrm{Co}^{2+}: 16.80 \mathrm{~g} / \mathrm{l}\right)$, a sodium carbonate solution $(200 \mathrm{~g} / \mathrm{l})$ prepared from sodium carbonate with $99.5 \%$ in purity and a surfactant as nucleation agent and emulsifying agent for the dispersion of the crystallites precipitate were used as reagents.

\subsection{Experimental Equipments}

A $600 \mathrm{ml}$ beaker, a $50 \mathrm{ml}$ graduated burette, a $250 \mathrm{ml}$ volumetric flask, a watch glass, an OHAUS branded precision weighing scale, a magnetic stirrer, a $\mathrm{pH}$ meter HANNA Instruments branded and a filtration device (vacuum pump + filter paper + Buchner) were mainly used to carry out all the precipitation tests.

\subsection{Analysis Techniques}

The cobalt carbonate precipitate analysis was performed by X-Rays Fluorescence technique.

Crystallization and particle size

The crystallization of generated precipitates was observed using D2 Phaser BRUKER X-Rays Diffractometer equipment; whereas the size of the crystallites was assessed according to the Laue-Scherrer Formula (1):

$$
d=\frac{K \lambda}{\beta \cos \theta}
$$

With:

- $K$ : coefficient $[K=0.9]$ 
- $\quad \lambda$ : wavelength of $\mathrm{K} \alpha \mathrm{Cu}$ X-ray [1542 $\AA$ ]

- $\quad \beta$ : Full width at half maximum: FWHM [rad]

- $\theta$. half of the diffraction angle of the wave [rad]

Scanning Electron Microscopy (SEM) was also used to observe the structure of the obtained precipitates.

\subsection{Precipitation Tests}

A preliminary precipitation test was conducted without surfactant and four additional tests were performed by varying two parameters (weight of surfactant agent and precipitation time) at two levels in accordance with Taguchi's L4 full experimental procedure $\left(2^{2}\right)$ given in Table 1 below.

Both parameters were chosen to control and limit the growth of generated cobalt carbonate crystallites.

\section{Results and Discussion}

\subsection{Preliminary Test without Surfactant}

A preliminary test was carried out without the use of surfactant in order to demonstrate the importance of surfactant agent in cobalt carbonate nanocrystals production.

Analysis of the obtained cobalt carbonate precipitates had yielded results on crystallization, purity and size as follows:

1) Crystallization

The sample of cobalt carbonate precipitated without surfactant gave the DRX spectrum shown on Figure 1 below.

(Coupled Two Theta/Theta)

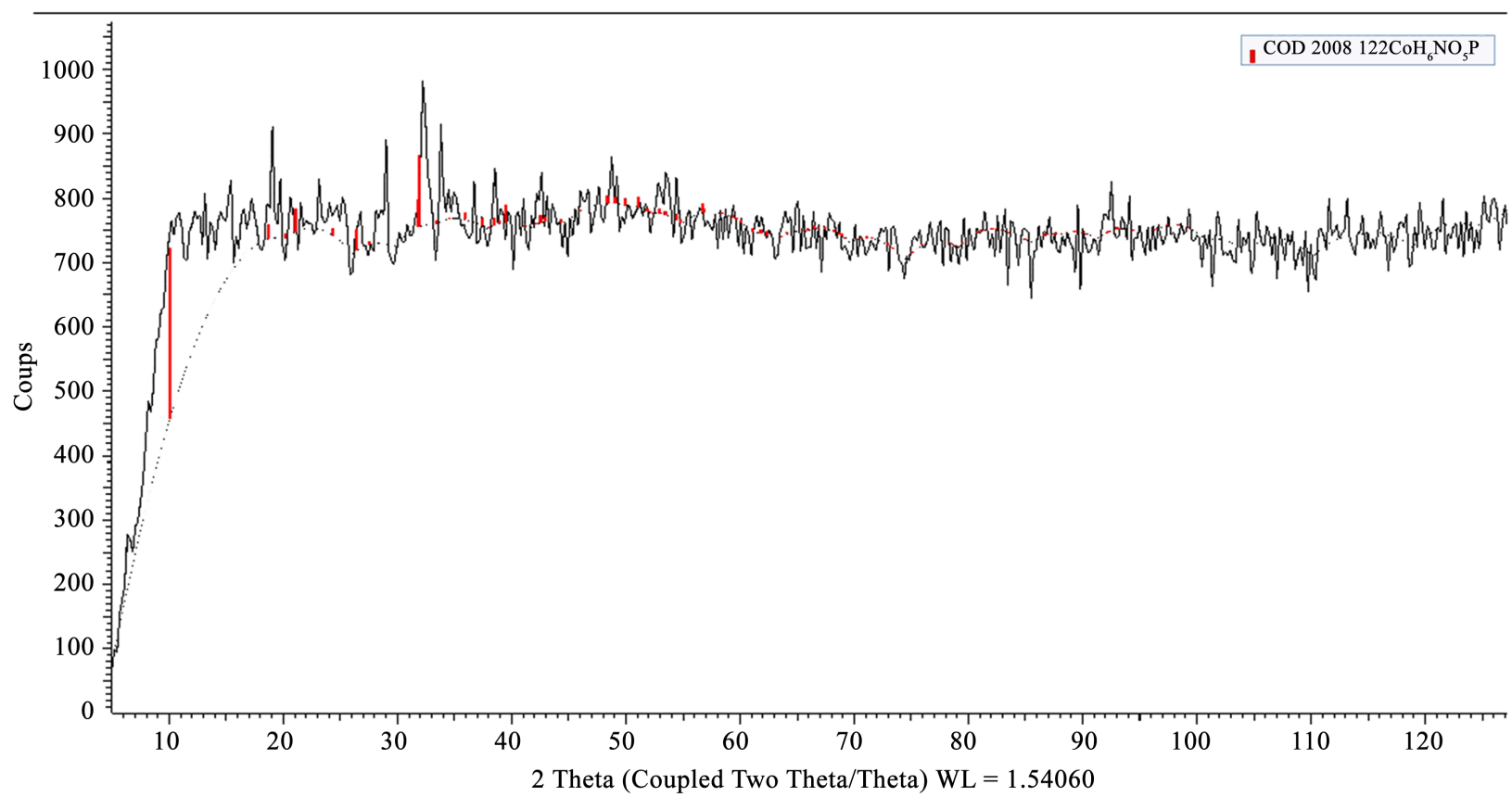

Figure 1. XRD spectrum of cobalt carbonate without surfactant. 
Table 1. Full L4 Taguchi's experiment plan.

\begin{tabular}{cc}
\hline Surfactant weight $[\mathrm{g}]$ & Time $[\mathrm{min}]$ \\
\hline 4 & 10 \\
4 & 20 \\
8 & 10 \\
8 & 20 \\
\hline
\end{tabular}

This spectrum shows, through the absence of characteristic peaks, a low crystallization or even an absence of crystallization of the obtained cobalt carbonate; which could be assimilated to an irregular or amorphous form of cobalt carbonate. This result sufficiently proves the importance of using additives in order to control the shape of the precipitate.

2) Purity

Chemical analysis by XRF of the obtained precipitate without surfactant had yielded a cobalt content of $36.80 \%$; which corresponds to a purity of $74.27 \%$ in cobalt carbonate.

3) Size

Due to the irregular shape of the obtained cobalt carbonate, it was almost impossible to calculate the size of the crystallites using the Laue-Scherrer formula. SEM analysis gave a cobalt carbonate crystallite size greater than $100 \mathrm{~nm}$ as shown by the micrograph in Figure 2 below.

\subsection{Orientation Test Using a Surfactant}

An orientation test was performed with a surfactant agent in order to assess its effects on the size and the structure of the crystals.

1) Crystallization

Analysis of the obtained cobalt carbonate with surfactant gave the XRD spectrum shown above in Figure 3 and Figure 4.

These figures indicate the presence of cobalt carbonate peaks. Therefore, the obtained precipitate has a crystalline structure with the specifications given by XRD's interface showing a rhombohedral crystalline system of $5.67 \mathrm{~A}^{\circ}$ as mesh dimension.

2) Purity

Chemical analysis of the obtained cobalt carbonate in presence of a surfactant through XRF yielded a cobalt content of $44.35 \%$ (equivalent to $89.45 \%$ of Co$\mathrm{CO}_{3}$ ).

From Figure 3 and Figure 4, it appears that there is still 36.9\% of amorphous phase and the rest being crystalline; and in the crystalline phase, there are $57.97 \%$ of $\mathrm{CoCO}_{3}, 36.63 \%$ of $\mathrm{Co}_{3} \mathrm{O}_{4}$ and $5.40 \%$ of $\mathrm{CoO}$. The presence of two oxides before calcination could be explained by uncontrolled conditions during drying which could have led to the start of calcination. However, the drying should imperatively be carried out in a neutral and controlled atmosphere [14]. 


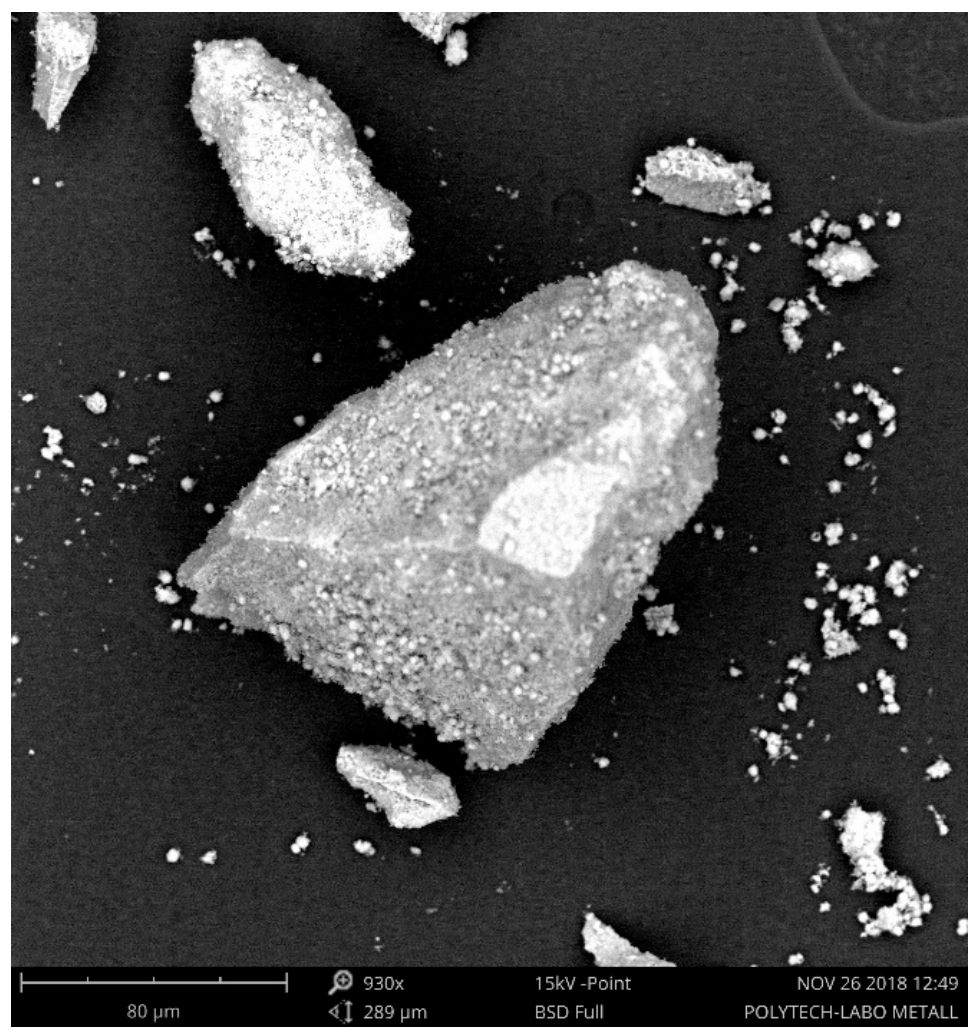

Figure 2. SEM image of cobalt carbonate without surfactant.

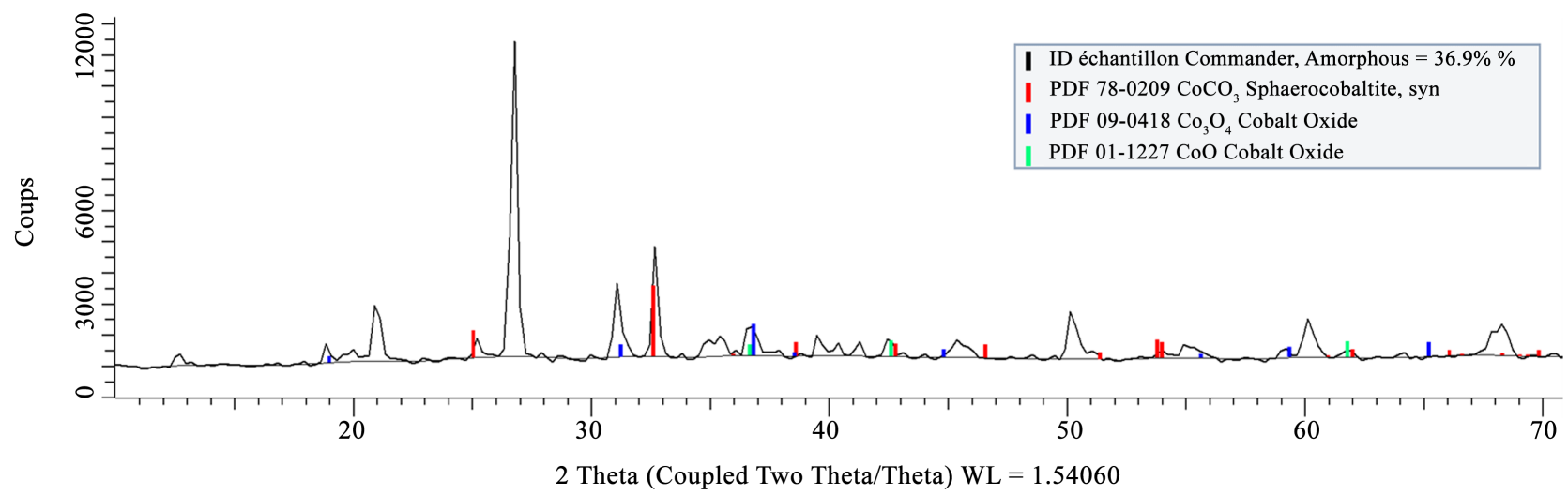

Figure 3. Cobalt carbonate Spectrum with surfactant agent using EVA.

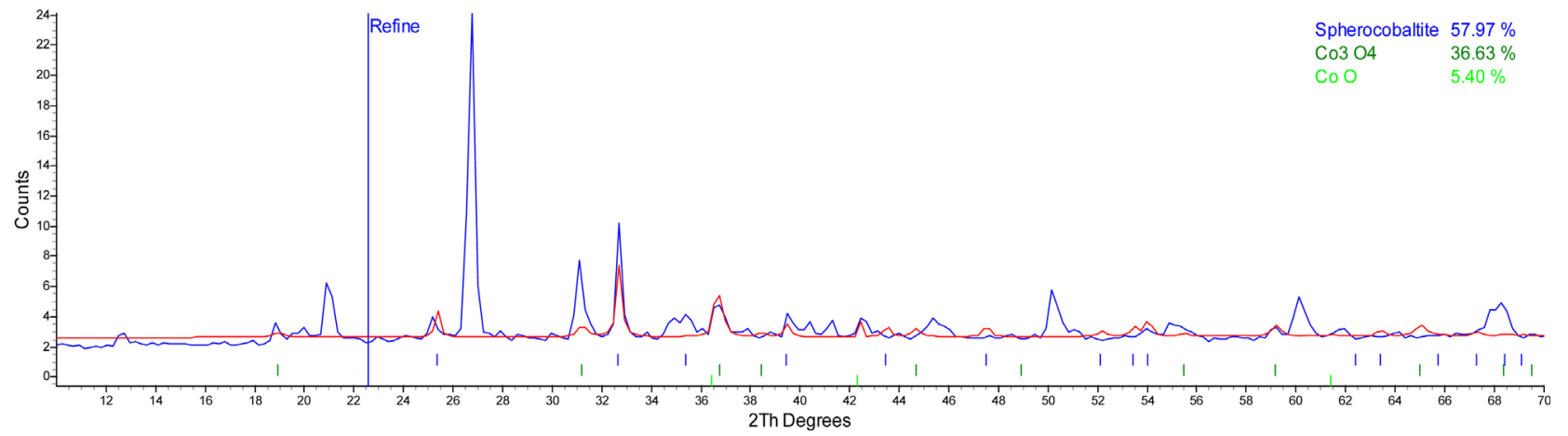

Figure 4. Cobalt carbonate Spectrum with surfactant agent by rietveld refining using Topas. 
The presence of the amorphous part in the nanocrystals could be explained by the insufficient quantity of germination sites in the reaction medium. The precipitation of cobalt carbonate under normal conditions in aqueous media leads primarily to an amorphous cobalt carbonate [16] [22]-[29]; thus the surfactant added in the medium played on control of shape and structure.

3) Size

Size of the obtained cobalt carbonate crystallites by considering all characteristic peaks of cobalt carbonate is given in Table 2 below which indicates a crystallite size of about $27.104 \mathrm{~nm}$. This is a clear indication of beneficial effects of using a surfactant agent to improve crystallite size as compared to results without surfactant [30].

\subsection{Influence of Surfactant's Weight and Precipitation Time on Nanocrystals}

Cobalt carbonate's crystallites size and purity results obtained by varying the weight of surfactant in the solution and the precipitation time according to $\mathrm{Ta}$ ble 1, are given in Table 3 below.

The effects of varying these key parameters are shown on Figure 5 below.

Under these conditions, optimal value of the crystallite size, could be predicted following the model below [11] [31]:

$$
Y_{\text {opt }}=\frac{T}{N}+\left(A_{i}-\frac{T}{N}\right)+\left(B_{j}-\frac{T}{N}\right)
$$

With:

Table 2. Carbonate cobalt nanocrystals size with surfactant.

\begin{tabular}{|c|c|c|c|c|c|}
\hline \multicolumn{6}{|c|}{ Conditions } \\
\hline- & \multicolumn{2}{|c|}{ Tube: Cu tube with $1.54184 \AA$} & - & \multicolumn{2}{|l|}{$10^{\circ} \leq 2 \theta \leq 127^{\circ}$} \\
\hline- & \multicolumn{2}{|c|}{ Detector: SSD160 (1D mode) } & - & \multicolumn{2}{|c|}{ Duration per point: $3 \mathrm{~s}$} \\
\hline- & \multicolumn{2}{|l|}{ Voltage: $30 \mathrm{kV}$} & - & \multicolumn{2}{|c|}{ Total duration: $1617 \mathrm{~s}$} \\
\hline- & \multicolumn{2}{|l|}{ Intensity: $10 \mathrm{~mA}$} & - & \multicolumn{2}{|l|}{ Rotation: $10 \mathrm{rpm}$} \\
\hline Pics & Left angle $\left[{ }^{\circ}\right]$ & Right angle $\left[{ }^{\circ}\right]$ & $2 \theta\left[^{\circ}\right]$ & FWHM [ $\left.{ }^{\circ}\right]$ & Size $[\mathrm{nm}]$ \\
\hline 1 & 27.741 & 25.648 & 25.205 & 0.305 & 29.62 \\
\hline 2 & 31.998 & 33.359 & 32.684 & 0.267 & 34.43 \\
\hline 3 & 41.976 & 42.884 & 42.538 & 0.435 & 21.80 \\
\hline 4 & 53.542 & 54.222 & 54.003 & 0.301 & 32.97 \\
\hline \multirow[t]{2}{*}{5} & 61.252 & 62.386 & 61.803 & 0.616 & 16.70 \\
\hline & & Average & & & 27.104 \\
\hline
\end{tabular}

Table 3. Crystallite size and purity of $\mathrm{CoCO}_{3}$ using a surfactant.

\begin{tabular}{ccc}
\hline Test & Size $(\mathrm{nm})$ & Co [\%] \\
\hline 1 & 15.29 & 45.30 \\
2 & 20.21 & 44.35 \\
3 & 1057 & 43.20 \\
4 & 16.19 & 43.32 \\
\hline
\end{tabular}




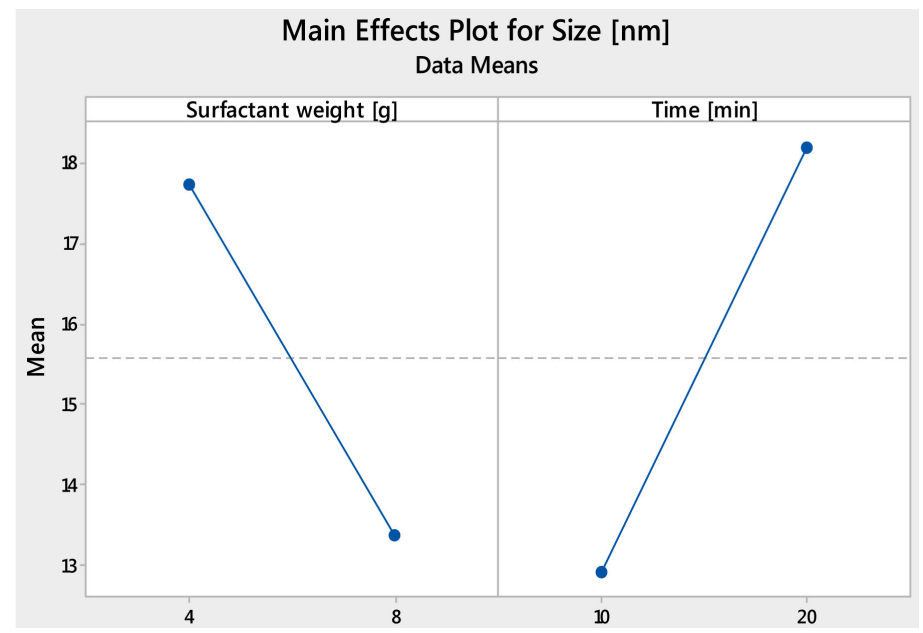

Figure 5. Influence of surfactant weight and precipitation time on crystallite size.

- $Y_{\text {opt }}$ the size of the crystallites at the optimal values of the parameters

- $\quad T$ : the sum of all the tests response

- $\quad N$ : the number of tests performed

- $A_{i}, B_{j}$ the average of tests response at the optimal value of each of the two parameters

The substitution of the aforementioned parameters in Equation (2), resulted in crystallites size estimation of about $13 \mathrm{~nm}$ which corresponds to a cobalt carbonate grain size reduction of $72.90 \%$ as compared to results without surfactant.

\subsection{Observations}

From Figure 5, some interpretations of the results could be given:

- The two parameters investigated through this work i.e., the weight of surfactant in the medium and the reaction time are both directly proportional to the weight of the obtained precipitate. Thus, the more surfactant is added to the solution, the more cobalt carbonate precipitate will be formed; the longer the reaction time is, the more cobalt carbonate precipitate will be formed. These results could be explained by the number of germination sites present in the medium as well as by the allowed crystals' growth time. It is important to note that the presence of a large quantity of surfactant in the solution, whose role is to create heterogeneous germination sites, could facilitate a high germination rate and subsequently lead to the obtention of many nuclei whose growth in a given lapse of time influences their final weight.

- The greater the surfactant weight in the precipitation solution, the smaller the obtained crystallite size. This could be explained by one of the ideal conditions for obtaining nanoscale crystals. Indeed, Wiswanatha, R. and Sarma, D. have shown that the obtention of nanocrystals is facilitated by a very high germination rate during a very short dispersing time of period these particles; therefore the presence of an optimal amount of surfactant fulfilling both roles i.e., high germination rate and short dispersing time, could be favourable to the reduction of cobalt carbonate crystals size [12] [13] [32]-[41]. 


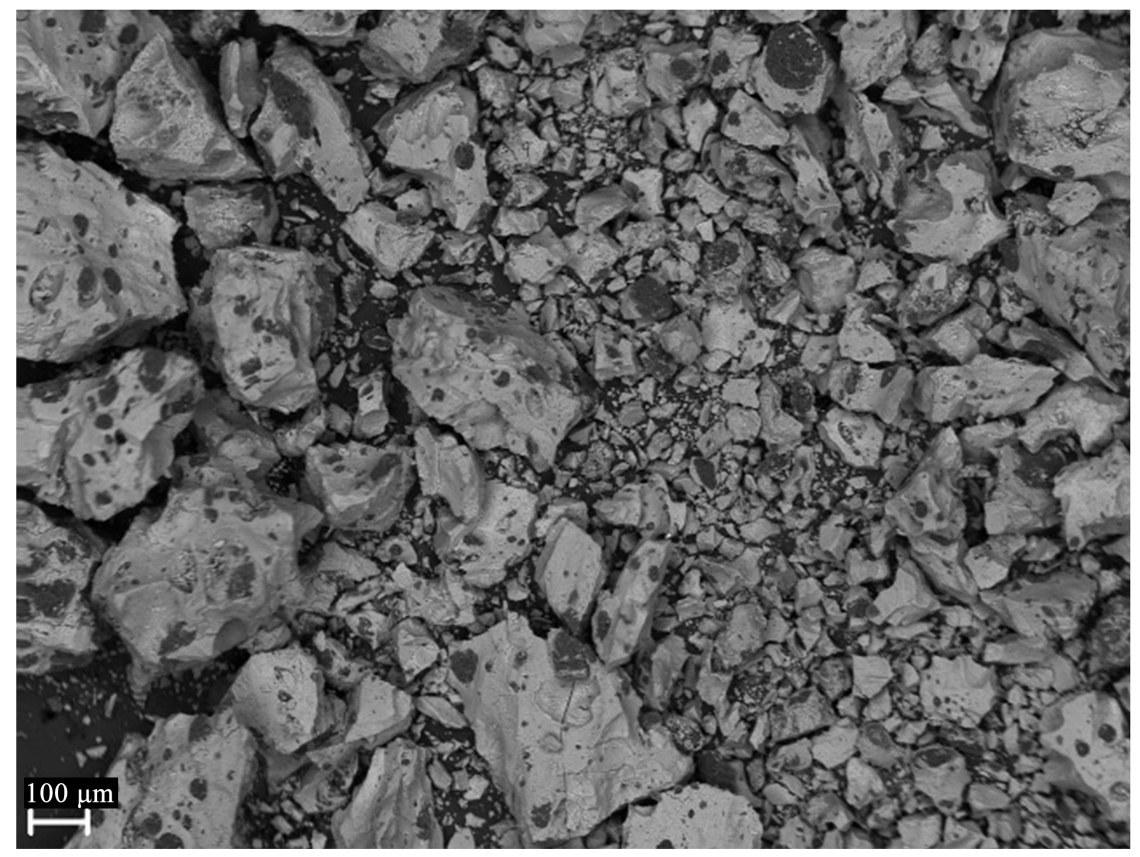

Figure 6. SEM image of the obtained cobalt carbonate nanocrystals.

- The longer the precipitation time, the larger the particles size become. This observation could be attributed to crystallite growth that occurs continuously as function of precipitation time.

Although the determination of crystallites sizes according to Equation (1) indicated nanometric dimensions of particles; SEM images showed an agglomeration of these particles (Figure 6) which could be associated with drying conditions. Better drying conditions can be achieved under neutral atmosphere and at a temperature below that of cobalt carbonate decomposition $\left(181.41^{\circ} \mathrm{C}\right)$.

\section{Conclusions}

Through this study, the importance of adding a microemulsion agent in order to control the structure and size of cobalt carbonate nanocrystals obtained from the reaction of a pure and rich sulphate cobalt solution $\left(\mathrm{Co}^{2+}: 16.80 \mathrm{~g} / \mathrm{l}\right)$ with sodium carbonate solution $(200 \mathrm{~g} / \mathrm{l})$ was demonstrated.

A systematic study was conducted by varying the weight of surfactant agent and the precipitation time in accordance with Taguchi's L4 full experimental procedure $\left(2^{2}\right)$. The obtained results under optimal conditions have indicated 13 $\mathrm{nm}$ as optimal size of cobalt carbonate nanocrystals with a cobalt content of $44.35 \%$ cobalt. However, further experiments are yet to be performed in order to eliminate the agglomeration of nanocrystals particles by optimizing drying conditions.

\section{Conflicts of Interest}

On behalf of all authors, the corresponding author states that there is no conflict of interest. 


\section{References}

[1] Bedre, M., et al. (2009) Preparation and Characterization of Cobalt Oxide Nanoparticles via Solution Combustion Method. Nano Science and Nano Technology: An Indian Journal, 3, 5-8.

[2] Mohammad, F. (2013) Synthesis of Nano-Sized Cobalt Oxide Nano-Particles Stabilized in Surfactant and Polymer Matrix and Their Magnetic Properties. Thesis, Faculty of Graduate Studies, An-Najah National University, Nablus.

[3] Liu, F., et al. (2017) Facile Synthesis of Ultrafine Cobalt Oxide Nanoparticles for High-Performance Supercapacitors. Journal of Colloid and Interface Science, 505, 796-804. https://doi.org/10.1016/j.jcis.2017.06.058

[4] Sharifi, S., et al. (2013) Characterization of Cobalt Oxide $\mathrm{Co}_{3} \mathrm{O}_{4}$ Nanoparticles Prepared by Various Methods: Effect of Calcination Temperature on Size, Dimension and Catalytic Decomposition of Hydrogen Peroxide. International Journal of $\mathrm{Na}$ nosciences and Nanotechnologies, 9, 51-58.

[5] Wenyao, S. and Mengwen, G. (2017) Solvothermal Synthesis of Cobalt Oxides Nanocristals. American Institute of Physics, College Park, 5 p.

[6] Desforges, A. (2004) Nucléation et croissance de nanoparticules métalliques dans une matrice organique poreuse: Application à la catalyse. Thèse de doctorat, Ecole doctorale des sciences chimiques, Université de Bordeaux I, Bordeaux.

[7] Kundu, S. and Jayachandran, M. (2013) Shape-Selective Synthesis of Non-Micellar Cobalt Oxide ( $\mathrm{CoO})$ Nanomaterials by Microwave Irradiations. Journal of Nanoparticle Research, 15, 1543. https://doi.org/10.1007/s11051-013-1543-3

[8] Sinkó, K., et al. (2011) Liquid-Phase Synthesis of Cobalt Oxide Nanoparticles. Journal of Nanoscience and Nanotechnology, 11, 1-9.

https://doi.org/10.1166/jnn.2011.3875

[9] Zhao, S., et al. (2015) Cobalt Carbonate Dumbbells for High-Capacity Lithium Storage: A Slight Doping of Ascorbic Acid and an Enhancement in Electrochemical Performances. Journal of Power Sources, 284, 154-161.

https://doi.org/10.1016/j.jpowsour.2015.03.016

[10] Chen, H., et al. (2002) Synthesis and High Rate Properties of Nanoparticle Lithium Cobalt Oxides as the Cathode Material for Lithium-Ion Battery. Electrochemistry Communications, 4, 488-491. https://doi.org/10.1016/S1388-2481(02)00357-0

[11] Rahimi-Nasrabadi, M., et al. (2017) Cobalt Carbonate and Cobalt Oxide Nanoparticles Synthesis, Characterization and Supercapacitive Evaluation. Journal Mater Science: Mater Electron, 28, 1877-1888. https://doi.org/10.1007/s10854-016-5739-z

[12] Portal, L. (2013) Synthèse et caractérisation structurale de nanocristaux d'oxydes métalliques. Thèse de doctorat, Faculté des Sciences et Techniques, Université de Limoges, Limoges.

[13] Rizet, L. and Charpentier, P. (2002) Techniques de l'ingénieur: Métallurgie extractive et recyclage des métaux de transition.

[14] Singh, M., et al. (2014) Synthesis, Characterization, Scale-Up and Catalytic Behaviour of $\mathrm{Co}_{3} \mathrm{O}_{4}$ Nanoparticles. Bulletin of Materials Science, 38, 297-301. https://doi.org/10.1007/s12034-015-0872-5

[15] Vayssieres, L. and Manthiram, A. (2004) One-Dimensional Metal Oxide Nanostructures. In: Nalwa, H.S., Ed., Encyclopedia of Nanoscience and Nanotechnology, Volume 8, American Scientific Publishers, Stevenson Ranch, 147-166.

[16] Barthe, L. (2007) Synthèse et dépôt de nanoparticules métalliques dans un support 
poreux par imprégnation en voie sèche dans un lit fluidisé: Elaboration de catalyseurs supports. Thèse de doctorat, Institut National Polytechnique de Toulouse, Université de Toulouse, Toulouse.

[17] Morsy, S. (2014) Role of Surfactants in Nanotechnology and Their Applications. International Journal of Current Microbiology and Applied Sciences, 3, 237-260.

[18] Perrault, V. (2007) Effet de la composition et de la structure des matrices alimentaires élaborées à partir de protéines laitières (Emulsions, Gels) sur la libération d'arôme, Diplôme d'Etudes Approfondies, Sciences et technologies des aliments. Faculté des Etudes Supérieures, Université Laval, Québec.

[19] Viswanatha, R. and Sarma, D. (2007) Growth of Nanocrystals in Solution. In: Nanomaterials Chemistry, Wiley, Hoboken, 139-170.

https://doi.org/10.1002/9783527611362.ch4

[20] Sun, Y.-Z., et al. (2009) Seeded Induction Period and Secondary Nucleation of Lithium Carboante. The Chinese Journal of Processing Engineering, 9, 652-660.

[21] Zhang, X., et al. (2010) Hydrothermal Microemulsion Synthesis of Oxidatively Stable Cobalt Nanocrystals Encapsulated in Surfactant/Polymer Complex Shells. Langmuir, 26, 6009-6014. https://doi.org/10.1021/la9045918

[22] Dial, A., et al. (2018) Cobalt: Demand-Supply Balances in the Transition to Electric Mobility. JRC Science for Policy Report, European Commission, Brussels, 104 p.

[23] González-López, J., et al. (2015) Crystal Structure of Cobalt Hydroxide Carbonate $\mathrm{Co}_{2} \mathrm{CO}_{3}(\mathrm{OH})_{2}$ : Density Functional Theory and X-Ray Diffraction Investigation. Acta Crystallographica Section B Structural Science, 73, 868-873.

[24] González-López, J., et al. (2016) Precipitation of $\mathrm{Co}^{2+}$ Carbonates from Aqueous Solution: Insights on the Amorphous to Crystalline Transformation. Geophysical Research Abstracts, 18, EGU2016-16057.

[25] Alex, P., et al. (2011) Synthesis of Cobalt Nano Crystals in Aqueous Media and Its Characterization. Materials Sciences and Applications, 2, 1307-1312. https://doi.org/10.4236/msa.2011.29177

[26] Allaedini, G. and Muhammad, A. (2013) Study of Influential Factors in Synthesis and Characterization of Cobalt Oxide Nanoparticles. Journal of Nanostructure in Chemistry, 3, 77. https://doi.org/10.1186/2193-8865-3-77

[27] Caillet, C. (2000) Solubilisation dans des micelles inverses et des vesicules: Influence des caractéristiques du film amphiphile. Thèse de doctorat, Faculté des Sciences, Université de Lorraine, Lorraine.

[28] Chee, K., et al. (2011) Synthesis of Cobalt Nano Particles on Silica Support Using the Strong Electrostatic Adsorption (SEA) Method. Defect and Diffusion Forum, 312, 370-375. https://doi.org/10.4028/www.scientific.net/DDF.312-315.370

[29] Cheftel, J. and Lorient, D. (1982) Aspects technologiques: Les propriétés fonctionnelles des protéines laitières et leur amélioration. Le Lait, 62, 435-483. https://doi.org/10.1051/lait:1982617-62029

[30] Wang, H., et al. (2010) Shape-Controlled Synthesis of Cobalt Oxide Nanocrystals Using Cobalt Acetylacetone. Materials Letters, 64, 408-410.

https://doi.org/10.1016/j.matlet.2009.11.034

[31] Athawale, A., et al. (2010) Synthesis of Cobalt Oxide Nanoparticles/Fibres in Alcoholic Medium Using $\gamma$-Ray Technique. Defence Science Journal, 60, 507-513. https://doi.org/10.14429/dsj.60.574

[32] Dazzazi, A. (2013) Synthèse et caractérisation de nanoparticules d'oxydes métalliques par voie organométallique: Vers des applications biomédicales. Thèse de doctorat, 
Chimie Organométallique, Université de Toulouse, Toulouse.

[33] Hocquard, J., et al. (2014) Panorama 2013 du marché du cobalt. Rapport public, BRGM/RP-63626-FR, 155 p.

[34] Izu, N., et al. (2017) Synthesis of Spherical Cobalt Oxide Nanoparticles by a Polyol Method. Journal of the Ceramic Society of Japan, 125, 701-704. https://doi.org/10.2109/jcersj2.17114

[35] Kumar, N. and Vijaya, K. (2016) Effect of $\mathrm{Bi}^{3+}$ Ion Substitution on Magnetic Properties of Cobalt Nano Ferrites Prepared by Sol-Gel Combustion Method. Soft Nanoscience Letters, 6, 37-44. https://doi.org/10.4236/snl.2016.63004

[36] Linxiao, G., et al. (2018) Electrochemical Characterization of Lithium Cobalt Oxide within Aqueous Flow Suspensions as an Indicator of Rate Capability in Lithium-Ion Battery Electrodes. Electrochimica Acta, 281, 822-830.

[37] Liu, Q., et al. (2009) Dry Citrate-Precursor Synthesized Nanocrystalline Cobalt Oxide as Highly Active Catalyst for Total Oxidation of Propane. Journal of Catalysis, 263, 104-113. https://doi.org/10.1016/j.jcat.2009.01.018

[38] Luisetto, I. and Bemporad, E. (2008) Preparation and Characterization of Nano Cobalt Oxide. Journal of Nanoparticle Research, 10, 59. https://doi.org/10.1007/s11051-008-9365-4

[39] Singh, M. and Mei, E.L.H. (2013) Surfactants and Their Use in Latex Technology. Rubber Technology Developments, 13, 33-36.

[40] Mauro, M., et al. (2015) Cobalt Oxide Nanoparticles: Behavior towards Intact and Impaired Human Skin and Keratinocytes Toxicity. International Journal of Environmental Research and Public Health, 12, 8263-8280. https://doi.org/10.3390/ijerph120708263

[41] Mollard, P., et al. (1971) Propriétés magnétiques de l'oxyde de cobalt CoO en grains fins. Journal de Physique Colloques, 32, 1041-1042.

https://doi.org/10.1051/jphyscol:19711373 